\title{
Effect of various supplementary cementitious materials on rheological properties of self-consolidating concrete
}

\author{
Reza Saleh Ahari ${ }^{\mathrm{a}, *}$, Tahir Kemal Erdem ${ }^{\mathrm{b}}$, Kambiz Ramyar ${ }^{\mathrm{a}}$ \\ ${ }^{a}$ Department of Civil Engineering, Ege University, Izmir, Turkey \\ ${ }^{\mathrm{b}}$ Department of Civil Engineering, Izmir Institute of Technology, Izmir, Turkey
}

\section{H I G H L I G H T S}

- The effect of binder type and content on the benefits of SCM in SCC was investigated.

- Metakaolin was able to increase the plastic viscosity of SCC by $90 \%$.

- Silica fume and blast furnace slag reduced the plastic viscosity of SCC.

- Yield stress of the mixtures with SCM was higher than that of the control mixtures.

\section{A R T I C L E I N F O}

Article history:

Received 16 September 2013

Received in revised form 7 November 2014

Accepted 8 November 2014

Available online 26 November 2014

\section{Keywords:}

Self-consolidating concrete

Supplementary cementitious materials

Rheology

Plastic viscosity

Yield stress

HRWR demand

\begin{abstract}
A B S T R A C T
In design of self-consolidating concrete (SCC) for a given application, the mixture's rheological parameters should be adjusted to achieve a given profile of yield stress and plastic viscosity. Supplementary cementitious materials (SCM) can be useful for this adjustment in addition to their other advantages. In this study, the rheological properties of 57 SCC mixtures with various SCM were investigated for a constant slump flow value. For this aim, various amounts of silica fume (SF), metakaolin (MK), Class F fly ash (FAF), Class C fly ash (FAC) and granulated blast-furnace slag (BFS) were utilized in binary, ternary, and quaternary cementitious blends in three water/binder ratios. Results showed that SF and BFS decreased plastic viscosity and V-funnel time values in comparison with mixtures containing only Portland cement (PC). However the opposite tendency was observed when MK, FAC and FAF were incorporated with PC. Substitution of PC with SF, MK and FAC increased high range water reducer (HRWR) demand in the SCC mixtures having constant slump flow. Use of SCM in SCC mixtures increased yield stress values. Good correlations were established between plastic viscosity and V-funnel flow time values for all $w / b$ ratios.
\end{abstract} (c) 2014 Elsevier Ltd. All rights reserved.

\section{Introduction}

SCC is one of the innovative concrete that is progressively used for experimental jobs and actual projects. It can flow readily under its own weight and self-consolidate without any mechanical vibration. Such a concrete must achieve magnificent deformability, and great stability to ensure high filling capacity of the formwork, even in a very congested structural member.

Yield stress and plastic viscosity are considered as two main parameters that define concrete rheology. SCC has a low yield stress and a moderate viscosity to ensure good consolidation and a highly fluid mixture without any segregation among constituents, especially between the binder phase and aggregate. A low yield stress and a moderate viscosity can be achieved by

\footnotetext{
* Corresponding author. Tel.: +90 23238860 26; fax: +90 2323425629

E-mail address: rsalehahari@mail.ege.edu.tr (R. Saleh Ahari).
}

an increase in paste volume for a given rheology of paste and dosage of high-range water-reducer (HRWR) [1-3]. One of the ways to increase the paste volume is to replace some part of the Portland cement (PC) with supplementary cementitious materials (SCM). In addition to the enhancement of mechanical properties and durability, the use of SCM, such as silica fume (SF), fly ash (FA), metakaolin (MK) and granulated blast-furnace slag (BFS) can improve rheological properties by adjusting the rheological parameters for a given application. In other words, plastic viscosity or yield stress can be tailored according to the desired performance in a variety of civil engineering applications by the utilization of SCM. Moreover, use of by-product SCM, like FA and BFS, can decrease the cost of SCC and the amount of the $\mathrm{CO}_{2}$ production related to the use of PC in concrete [4-13].

Despite the above-mentioned advantages of SCM in SCC, they may also weaken SCC properties compared to the plain SCC containing no SCM. For instance, SF and MK significantly increase 
early strength and considerably reduce the permeability of SCC but may impair the required workability in fresh concrete. On the contrary, BFS generally decreases early strength but improves workability. Due to these opposite effects, combinations of SCM have found significant importance in concrete technology [1417]. Assaad [10] studied the rheological behavior of SCC containing $\mathrm{SF}, \mathrm{BFS}$ and $\mathrm{FA}$. It was reported that mixtures containing binary cement $(\mathrm{PC}+\mathrm{SF})$, ternary cement $(\mathrm{PC}+\mathrm{SF}+\mathrm{FA})$ and quaternary cement $(\mathrm{PC}+\mathrm{SF}+\mathrm{FA}+\mathrm{BFS})$ showed lower plastic viscosity values than corresponding plain SCC mixtures. In another research, the effects of SCM on the rheological properties of cement grouts were tested by Khayat et al. [6]. It was concluded that the partial substitutions of cement with FA and BFS increased the plastic viscosity compared to that of the reference grout made without any SCM, regardless of the HRWR dosage. However in the case of SF, decrease in plastic viscosity was visible.

In recent years, there has been a growing interest in the use of MK and SF as SCM to produce SCC. However, only a limited number of studies are available about the rheological properties of SCC containing MK. In a recent study, Hassan et al. [18] investigated the yield stress and plastic viscosity of SCC containing MK and SF. They proposed that the addition of MK and SF increased the HRWR demand in SCC mixtures having constant slump flow. Moreover, the addition of SF appeared to require more HRWR when compared to MK. It was also found that both plastic viscosity and yield stress increased as percentage of MK was increased. At constant slump flow, plastic viscosity of SF mixtures were similar to that of the control mixture without any SCM. When the HRWR content was kept constant, yield stress increased continuously with an increase in SF content. Besides, as cited by Hassan et al. [18], Mouret and Cyr [19] found that cement paste with MK exhibited high plastic viscosity while cement paste with SF showed lower plastic viscosity than reference cement paste. In another investigation Boukendakdji et al. [20] noted that the SCC mixtures incorporating BFS exhibited low plastic viscosity and low yield stress than the reference mixture containing only PC.

Although a number of studies about the effects of using FA, SF and BFS on the fresh and hardened properties of SCC have been found in the literature, the effect of using these SCM on the rheological properties were discussed only in limited number of studies $[10,18,21,22]$. Moreover, the potential benefit of using various amounts of SCM in ternary and quaternary combinations with PC on rheological properties of SCC is not well documented. The study presented herein aims at the effect of binder type and content on the benefits of SCM in SCC of different dispersion states that can be used in a variety of civil engineering applications.

The current study focuses on the rheological properties of SCC containing various amounts of SF, FA, MK and BFS as a partial replacement of cement. These SCM were used in binary, ternary, and quaternary cementitious blends to investigate the variations of some properties such as V-funnel flow time, HRWR demand as well as yield stress and plastic viscosity. The mixtures were designed to have three water-binder ratios $(w / b)$. The rheological parameters were measured with a coaxial cylinder concrete rheometer. This study also aims at comparing the effects of utilization of a viscosity modifying admixture (VMA) to those of SCM.

\section{Experimental methods}

\subsection{Materials}

An ordinary Portland cement CEM I 42.5 R, similar to ASTM C 150 [23] Type I cement, was used. Five types of SCM, which are SF, FAC, FAF, MK, and BFS, were also used in binary, ternary, and quaternary cementitious blends. The physical and chemical properties and particle-size distribution of PC, SF, FAF, MK, and BFS are presented in Table 1 and Fig. 1. In addition, the micrographs of SCM and PC are shown in Fig. 2. Crushed limestone was used as aggregate. The maximum particle
Table 1

Physical and chemical properties of cement and SCM.

\begin{tabular}{|c|c|c|c|c|c|c|}
\hline & PC & SF & FAC & FAF & MK & BFS \\
\hline $\mathrm{CaO}(\%)$ & 64.06 & 0.25 & 36.56 & 3.24 & 0.3 & 35.2 \\
\hline $\mathrm{SiO}_{2}(\%)$ & 17.74 & 87.92 & 31.94 & 59.5 & 51.1 & 40.3 \\
\hline $\mathrm{Al}_{2} \mathrm{O}_{3}(\%)$ & 4.76 & 0.4 & 13.5 & 18.5 & 39.1 & 10.2 \\
\hline $\mathrm{Fe}_{2} \mathrm{O}_{3}(\%)$ & 3.17 & 0.35 & 4.09 & 6.96 & 2.15 & 0.67 \\
\hline $\operatorname{MgO}(\%)$ & 1.28 & 3.97 & 1.42 & 2.03 & 0.7 & 6.9 \\
\hline $\mathrm{SO}_{3}(\%)$ & 2.94 & 0.21 & 3.86 & 0.47 & 0.08 & 1.4 \\
\hline $\mathrm{K}_{2} \mathrm{O}(\%)$ & 0.8 & 0.81 & 0.94 & 1.93 & 1.78 & 0.97 \\
\hline $\mathrm{Na}_{2} \mathrm{O}(\%)$ & 0.45 & 1.79 & 1.1 & 1.27 & 0.11 & 1.12 \\
\hline Free lime (\%) & 2.21 & - & 2.69 & 0.42 & - & - \\
\hline Other minor oxides (\%) & 0.64 & 1.43 & 0.91 & 1.26 & 0.88 & 1.34 \\
\hline Loss on ignition (\%) & 1.95 & 2.87 & 2.99 & 4.32 & 3.8 & 1.9 \\
\hline Specific gravity & 3.13 & 2.29 & 2.73 & 2.38 & 2.54 & 2.97 \\
\hline Blaine fineness $\left(\mathrm{cm}^{2} / \mathrm{g}\right)$ & 3310 & - & 3470 & 3220 & - & 3650 \\
\hline $\begin{array}{l}\text { Surface area B.E.T. } \\
\qquad\left(\mathrm{m}^{2} / \mathrm{kg}\right)\end{array}$ & - & 24,520 & - & - & 15,410 & - \\
\hline Residue $45 \mu \mathrm{m}(\%)$ & 4.2 & - & 17.4 & 19.5 & 0.4 & 1.3 \\
\hline
\end{tabular}

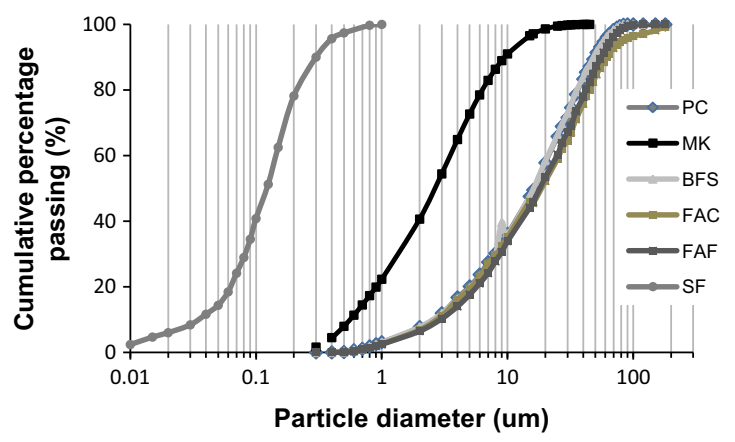

Fig. 1. Particle size distributions of PC and SCM.

size was $15 \mathrm{~mm}$ and $3 \mathrm{~mm}$ for coarse and fine aggregate, respectively. The bulk specific gravity of the coarse and fine aggregates were 2.64 and 2.61 , respectively, and their absorption capacities were $0.21 \%$ and $0.67 \%$, respectively. A polycarboxylate ether-based HRWR conforming to ASTM C494 Type F of [24] with a specific gravity of 1.1 and solid content of $28 \%$ was incorporated in all mixtures. A liquid viscositymodifying admixture (VMA) was used in some SCC mixtures.

\subsection{Mix proportions and preparation}

As summarized in Tables 2-4 a total of 57 SCC mixtures were designed to have three $w / b(0.44,0.50$, and 0.56$)$ with various binder contents $(454.5,400$, and $357 \mathrm{~kg} / \mathrm{m}^{3}$ ) and a constant water content. For all SCC mixtures the fine aggregateto-total aggregate ratio, by mass, was set at 0.53 . The HRWR dosages used in the mixtures were adjusted to secure an initial slump flow of $650 \pm 10 \mathrm{~mm}$. The three control mixtures did not contain any SCM, whereas other mixtures incorporated binary $(\mathrm{PC}+\mathrm{SF}, \mathrm{PC}+\mathrm{FAC}, \mathrm{PC}+\mathrm{FAF}, \mathrm{PC}+\mathrm{MK}$ and $\mathrm{PC}+\mathrm{BFS})$, ternary $(\mathrm{PC}+\mathrm{SF}+\mathrm{BFS}$, $\mathrm{PC}+\mathrm{FAC}+\mathrm{BFS}, \quad \mathrm{PC}+\mathrm{FAF}+\mathrm{BFS}$ and $\mathrm{PC}+\mathrm{MK}+\mathrm{BFS})$ and quaternary ( $\mathrm{PC}+\mathrm{SF}+$ $\mathrm{FAC}+\mathrm{BFS}$ ) cementitious blends in which a portion of $\mathrm{PC}$ was replaced with the SCM. The replacement levels for various SCM were different: it was $4 \%, 8 \%$ and $12 \%$ for $\mathrm{SF}, 4 \%, 8 \%, 18 \%$ and $36 \%$ for MK, $18 \%$ and $36 \%$ for FA and only $18 \%$ for BFS. In addition, a constant amount of VMA, selected within the recommended dosage range of the manufacturer, was employed for each $w / b$ ratio to compare the results with the mixtures containing SCM. All substitutions of the cement by SCM were made on the total mass basis of the binder. The mixtures were mixed in batches of $20 \mathrm{~L}$ using a rotary planetary mixer. Mixing efficiency, mixer type, mixing sequence, ambient temperature, etc. are the factors affecting the rheology of SCC during its production $[25,26]$. Therefore, these factors were not changed throughout the study. The mixing materials were kept at approximately $20 \pm 2{ }^{\circ} \mathrm{C}\left(68^{\circ} \mathrm{F}\right)$ temperature before mixing. Following the end of mixing, mixtures had approximately constant temperatures of $24 \pm 2^{\circ} \mathrm{C}\left(75.2^{\circ} \mathrm{F}\right)$. The mixing procedure for concrete mixtures consisted of homogenizing the fine and coarse aggregate for $1 \mathrm{~min}$ and introducing $35 \%$ of the mixing water. Following a rest period of 1 min to allow the saturation of the aggregates, binder and $40 \%$ of water were added. After 2 min of mixing, the HRWR diluted with the remaining water was introduced gradually over $2 \mathrm{~min}$. while the mixer was turned on. Following 2 min of rest, the concrete was mixed for 3 additional min.

The mix proportions of VMA-bearing mixtures were similar to that of the control mixtures except that VMA content was $4.6 \mathrm{~kg} / \mathrm{m}^{3}$ for all $w / b$ ratios and HRWR content was $8,6,5.48 \mathrm{~kg} / \mathrm{m}^{3}$ for $w / b$ ratios of $0.44,0.50$ and 0.56 , respectively. The 


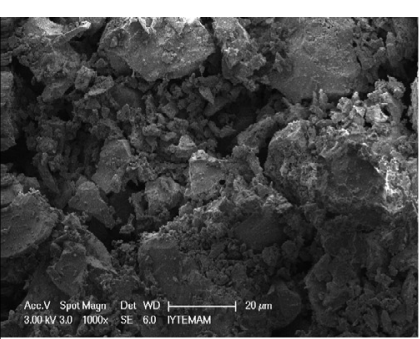

(a)



(d)

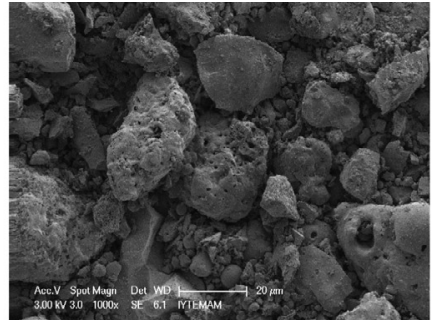

(b)

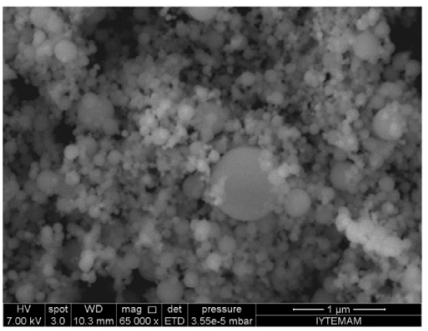

(e)

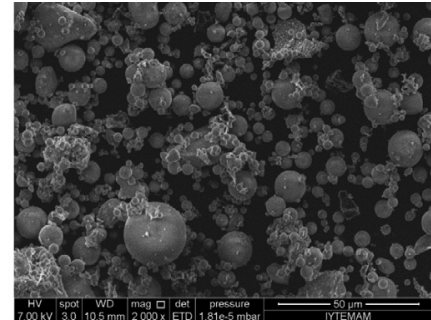

(c)

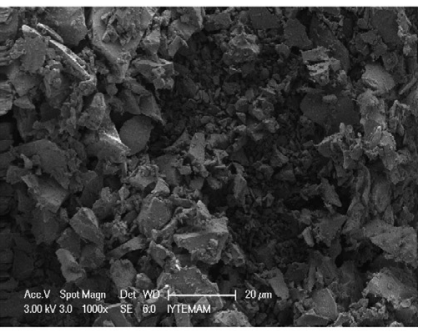

(f)

Fig. 2. SEM images of (a) PC, (b) FAC, (c) FAF, (d) MK, (e) SF and (f) BFS particles.

Table 2

Mix proportions of SCC mixtures having $w / b=0.44\left(\mathrm{~kg} / \mathrm{m}^{3}\right)$.

\begin{tabular}{|c|c|c|c|c|c|c|c|c|c|c|}
\hline \multirow[t]{2}{*}{ Mixture ID } & \multirow[t]{2}{*}{ Water } & \multirow[t]{2}{*}{ PC } & \multirow[t]{2}{*}{$\mathrm{SF}$} & \multirow[t]{2}{*}{ FAC } & \multirow[t]{2}{*}{ FAF } & \multirow[t]{2}{*}{ MK } & \multirow[t]{2}{*}{ BFS } & \multirow[t]{2}{*}{ HRWR } & \multicolumn{2}{|c|}{ Aggregates (SSD) } \\
\hline & & & & & & & & & Fine & Coarse \\
\hline Control & 200 & 454.5 & - & - & - & - & - & 5.75 & 883 & 783 \\
\hline $4 \mathrm{SF}$ & 200 & 436.5 & 18 & - & - & - & - & 6.70 & 880 & 778 \\
\hline $8 \mathrm{SF}$ & 200 & 418.5 & 36 & - & - & - & - & 7.50 & 875 & 774 \\
\hline $12 \mathrm{SF}$ & 200 & 400 & 54.5 & - & - & - & - & 8.0 & 870 & 771 \\
\hline 8SF18BFS & 200 & 337 & 36 & - & - & - & 81.5 & 6.70 & 874 & 774 \\
\hline $18 \mathrm{FAC}$ & 200 & 373 & - & 81.5 & - & - & - & 5.82 & 878 & 778 \\
\hline $36 \mathrm{FAC}$ & 200 & 291 & - & 163.5 & - & - & - & 6.35 & 872 & 773 \\
\hline 36FAC18BFS & 200 & 209.5 & - & 163.5 & - & - & 81.5 & 5.50 & 871 & 772 \\
\hline $18 \mathrm{FAF}$ & 200 & 373 & - & - & 81.5 & - & - & 4.67 & 872 & 772 \\
\hline $36 \mathrm{FAF}$ & 200 & 291 & - & - & 163.5 & - & - & 4.36 & 859 & 762 \\
\hline 36FAF18BFS & 200 & 209.5 & - & - & 163.5 & - & 81.5 & 4.31 & 858 & 761 \\
\hline $4 \mathrm{MK}$ & 200 & 436.5 & - & - & - & 18 & - & 6.18 & 881 & 781 \\
\hline $8 \mathrm{MK}$ & 200 & 418.5 & - & - & - & 36 & - & 6.50 & 878 & 779 \\
\hline $18 \mathrm{MK}$ & 200 & 373 & - & - & - & 81.5 & - & 7.50 & 873 & 773 \\
\hline $36 \mathrm{MK}$ & 200 & 291 & - & - & - & 163.5 & - & 10.0 & 861 & 762 \\
\hline 36MK18BFS & 200 & 209.5 & - & - & - & 163.5 & 81.5 & 9.35 & 860 & 761 \\
\hline 18BFS & 200 & 373 & - & - & - & - & 81.5 & 5.35 & 881 & 781 \\
\hline 8SF18FAC18BFS & 200 & 255.5 & 36 & 81.5 & - & - & 81.5 & 7.0 & 868 & 769 \\
\hline
\end{tabular}

Table 3

Mix proportions of SCC mixtures having $w / b=0.50\left(\mathrm{~kg} / \mathrm{m}^{3}\right)$.

\begin{tabular}{|c|c|c|c|c|c|c|c|c|c|c|}
\hline \multirow[t]{2}{*}{ Mixture ID } & \multirow[t]{2}{*}{ Water } & \multirow[t]{2}{*}{ PC } & \multirow[t]{2}{*}{$\mathrm{SF}$} & \multirow[t]{2}{*}{ FAC } & \multirow[t]{2}{*}{ FAF } & \multirow[t]{2}{*}{ MK } & \multirow[t]{2}{*}{ BFS } & \multirow[t]{2}{*}{ HRWR } & \multicolumn{2}{|c|}{ Aggregates (SSD) } \\
\hline & & & & & & & & & Fine & Coarse \\
\hline Control & 200 & 400 & - & - & - & - & - & 4.50 & 908 & 805 \\
\hline $4 \mathrm{SF}$ & 200 & 384 & 16 & - & - & - & - & 5.0 & 905 & 802 \\
\hline $8 \mathrm{SF}$ & 200 & 368 & 32 & - & - & - & - & 5.33 & 901 & 799 \\
\hline $12 S F$ & 200 & 352 & 48 & - & - & - & - & 6.33 & 897 & 795 \\
\hline 8SF18BFS & 200 & 296 & 32 & - & - & - & 72 & 4.80 & 900 & 798 \\
\hline $18 \mathrm{FAC}$ & 200 & 328 & - & 72 & - & - & - & 4.60 & 905 & 801 \\
\hline 36FAC & 200 & 256 & - & 144 & - & - & - & 5.05 & 900 & 797 \\
\hline 36FAC18BFS & 200 & 184 & - & 144 & - & - & 72 & 4.47 & 898 & 796 \\
\hline $18 \mathrm{FAF}$ & 200 & 328 & - & - & 81.5 & - & - & 4.0 & 899 & 796 \\
\hline $36 \mathrm{FAF}$ & 200 & 256 & - & - & 163.5 & - & - & 3.67 & 890 & 787 \\
\hline 36FAF18BFS & 200 & 184 & - & - & 163.5 & - & 72 & 3.65 & 889 & 786 \\
\hline $4 \mathrm{MK}$ & 200 & 384 & - & - & - & 16 & - & 4.85 & 906 & 803 \\
\hline $8 \mathrm{MK}$ & 200 & 368 & - & - & - & 32 & - & 5.10 & 904 & 801 \\
\hline $18 \mathrm{MK}$ & 200 & 328 & - & - & - & 72 & - & 6.0 & 899 & 797 \\
\hline 36MK & 200 & 256 & - & - & - & 144 & - & 8.0 & 889 & 788 \\
\hline 36MK18BFS & 200 & 184 & - & - & - & 144 & 72 & 7.45 & 888 & 787 \\
\hline 18BFS & 200 & 328 & - & - & - & - & 72 & 4.30 & 907 & 803 \\
\hline 8SF18FAC18BFS & 200 & 224 & 32 & 72 & - & - & 72 & 5.60 & 895 & 793 \\
\hline
\end{tabular}


Table 4

Mix proportions of SCC mixtures having $w / b=0.56\left(\mathrm{~kg} / \mathrm{m}^{3}\right)$.

\begin{tabular}{|c|c|c|c|c|c|c|c|c|c|c|}
\hline \multirow[t]{2}{*}{ Mixture ID } & \multirow[t]{2}{*}{ Water } & \multirow[t]{2}{*}{ PC } & \multirow[t]{2}{*}{$\mathrm{SF}$} & \multirow[t]{2}{*}{ FAC } & \multirow[t]{2}{*}{ FAF } & \multirow[t]{2}{*}{ MK } & \multirow[t]{2}{*}{ BFS } & \multirow[t]{2}{*}{ HRWR } & \multicolumn{2}{|c|}{ Aggregates (SSD) } \\
\hline & & & & & & & & & Fine & Coarse \\
\hline Control & 200 & 357 & - & - & - & - & - & 3.90 & 929 & 822 \\
\hline $4 \mathrm{SF}$ & 200 & 342.7 & 14.2 & - & - & - & - & 4.20 & 925 & 820 \\
\hline $8 \mathrm{SF}$ & 200 & 328.5 & 28.5 & - & - & - & - & 4.53 & 922 & 818 \\
\hline $12 \mathrm{SF}$ & 200 & 314.5 & 42.5 & - & - & - & - & 5.66 & 918 & 815 \\
\hline 8SF18BFS & 200 & 264.5 & 28.5 & - & - & - & 64 & 4.50 & 921 & 816 \\
\hline $18 \mathrm{FAC}$ & 200 & 293 & - & 64 & - & - & - & 4.0 & 925 & 818 \\
\hline 36FAC & 200 & 228.5 & - & 128.5 & - & - & - & 4.15 & 919 & 815 \\
\hline 36FAC18BFS & 200 & 164.5 & - & 128.5 & - & - & 64 & 4.0 & 918 & 814 \\
\hline $18 \mathrm{FAF}$ & 200 & 293 & - & - & 81.5 & - & - & 3.47 & 921 & 814 \\
\hline $36 F A F$ & 200 & 228.5 & - & - & 163.5 & - & - & 3.23 & 911 & 807 \\
\hline 36FAF18BFS & 200 & 164.5 & - & - & 163.5 & - & 64 & 3.20 & 910 & 806 \\
\hline $4 \mathrm{MK}$ & 200 & 342.7 & - & - & - & 14.25 & - & 4.10 & 927 & 822 \\
\hline $8 \mathrm{MK}$ & 200 & 328.5 & - & - & - & 28.5 & - & 4.20 & 925 & 820 \\
\hline $18 \mathrm{MK}$ & 200 & 293 & - & - & - & 64 & - & 5.26 & 920 & 816 \\
\hline $36 \mathrm{MK}$ & 200 & 228.5 & - & - & - & 128.5 & - & 7.20 & 911 & 807 \\
\hline 36MK18BFS & 200 & 164.5 & - & - & - & 128.5 & 64 & 6.80 & 909 & 805 \\
\hline 18BFS & 200 & 293 & - & - & - & - & 64 & 3.65 & 928 & 820 \\
\hline 8SF18FAC18BFS & 200 & 200.5 & 28.5 & 64 & - & - & 64 & 4.87 & 917 & 812 \\
\hline
\end{tabular}

identification of the mixtures was made according to the type and amount of SCM. For example, (8SF18FA18BFS) shows the quaternary mixture containing $8 \% \mathrm{SF}, 18 \%$ FA and $18 \%$ BFS.

\subsection{Testing procedure}

Immediately after the end of mixing ( 9 min after the initial contact of water with cement), slump flow diameter was measured. Then, rheology and V-funnel time testes were made in parallel. The slump flow values were represented by the mean diameter (measured from two perpendicular directions) of the concrete spread after lifting the standard slump cone. The V-funnel time test consisted of a V-shaped container with an opening of $65 \times 65 \mathrm{~mm}$ at the bottom and $500 \times 65 \mathrm{~mm}$ at the top. The rheological parameters were evaluated using a coaxial cylinder concrete rheometer (ConTec 4SCC). A four-bladed vane rotating coaxially was used for the impeller. The container of the rheometer had a diameter of $240 \mathrm{~mm}$ and a depth of $240 \mathrm{~mm}$, allowing a concrete sample volume of approximately $8 \mathrm{~L}$. The testing protocol consisted of increasing the impeller speed, $N$, gradually to 0.7 revolutions/s (rps) during $36 \mathrm{~s}$, subsequently reducing the speed stepwise to carry out the measurements of the torque, $T$, data. Each rotational velocity $(0.70,0.55,0.40,0.25$, and $0.10 \mathrm{rps})$ was maintained for $6 \mathrm{~s}$ to ensure breakdown of the structure. However, the torque values obtained during the last $5 \mathrm{~s}$ were used in calculating the average torque value corresponding to that speed. Since the rheometer can take 4 torque data per $1 \mathrm{~s}, 4 \times 4=16$ data were averaged. Hereby torque-rotational velocity chart (rheograph) was generated, for each concrete mixture. The torque-rotational velocity data in the descending curve were linear corresponding to a Bingham fluid, as follows: $T=g+h N$, where $\mathrm{g}(\mathrm{N} \mathrm{mm})$ and $\mathrm{h}$ $(\mathrm{N} \mathrm{mm} \mathrm{s})$ are coefficients related to apparent yield stress and torque plastic viscosity, respectively. A typical example of a rheograph is presented in Fig. 3. It can be deduced from this graph that torque-rotational velocity data are straight linear according to a Bingham fluid. In this figure slope of the linear fit and intercept with the torque axis were related to the torque plastic viscosity $(h)$ and apparent yield stress $(g)$, respectively. The linear fit always resulted in coefficient of correlation $\left(R^{2}\right)$ values greater than 0.92 . The $g$ and $h$ values obtained from such figures drawn for each mixture were turned to yield stress (Pa) and plastic viscosity (Pa s) after multiplying with special coefficients recommended by the manufacturer of the rheometer (yield stress $=0.18 * g$ and plastic viscosity $=0.017 * h$ ).

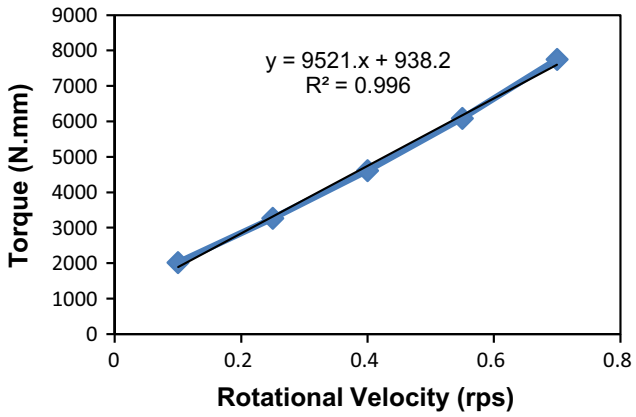

Fig. 3. An example rheograph

\section{Results and discussion}

\subsection{HRWR demand}

The HRWR concentrations to produce a $650 \mathrm{~mm}$ slump-flow diameter for each SCC mixture are illustrated in Fig. $4 a-c$. The partial replacement of PC by FAF and BFS decreased the HRWR requirement of when compared to the control mixture (see the mixtures at the left hand side of the control mixtures in these figures). Mixtures containing SF, MK and FAC showed more HRWR demand than the control mixtures. Incorporation of greater amounts of SF, MK and FAC present in binary, ternary, and quaternary cements increased the HRWR demand further, while, the opposite tendency was observed when cement was incorporated with FAF in binary and ternary cement blends (i.e. as the FAF content increased, the HRWR demand decreased).

As expected, in all of the $w / b$ ratios, SF and MK had higher HRWR demand to obtain constant slump flow value than other SCM. The effect was more pronounced in SF containing mixtures. For example, when $w / b=0.44$, HRWR demand increased by approximately $40 \%$ when the percentage of SF increased from $0 \%$ to $12 \%$ but the increase in HRWR demand was approximately $30 \%$ when the percentage of MK was changed from $0 \%$ to $18 \%$. Similar results are reported by other investigations $[18,27,28]$. The high HRWR demand of SF is probably due to extremely fine nature and high surface area of grain content (Fig. 2e).

The causes of increase in HRWR admixture demand upon MK incorporation were studied by several researches [29,30]. They concluded that very small MK particles, owing to their high surface energy, tend to agglomerate resulting in a high amount of HRWR necessary for the deflocculation of fine agglomerate particle system to lubricate the flowing system. Furthermore as shown in Fig. 2d, irregular structure, elongated shape and high surface area $\left(15,410 \mathrm{~m}^{2} / \mathrm{kg}\right)$ of MK particles can be related to the higher utilization of HRWR to obtain the target slump value.

When BFS was incorporated with other SCM to obtain ternary and quaternary systems, HRWR demand was lower when compared to the mixtures without BFS. This effect of BFS is mainly due to the morphology of glassy slag particles as well as their smooth surface, resulting in low adsorption potential (Fig. 2f).

For the mixtures containing VMA, it observed from Fig. $4 a-c$ that the HRWR demand was higher when compared to the control mixtures. These results are in agreement with other studies $[10,20,29,31]$. 
(a)

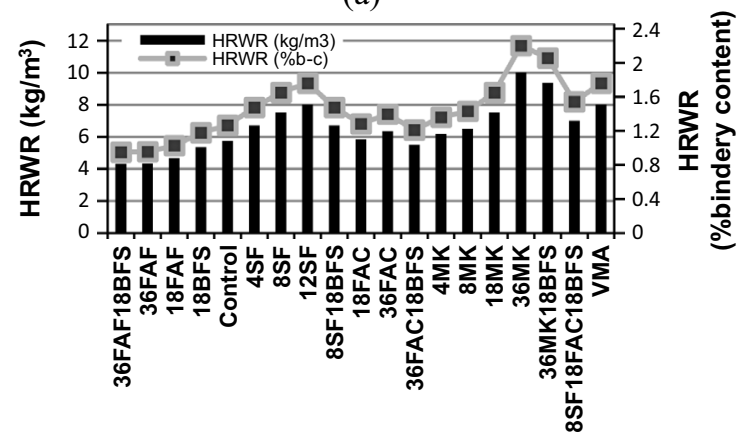

SCC Type

(c)

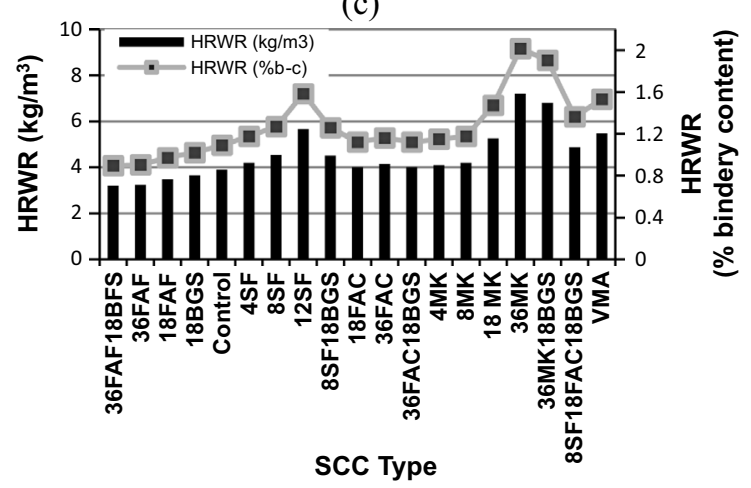

(b)



SCC Type

(d)

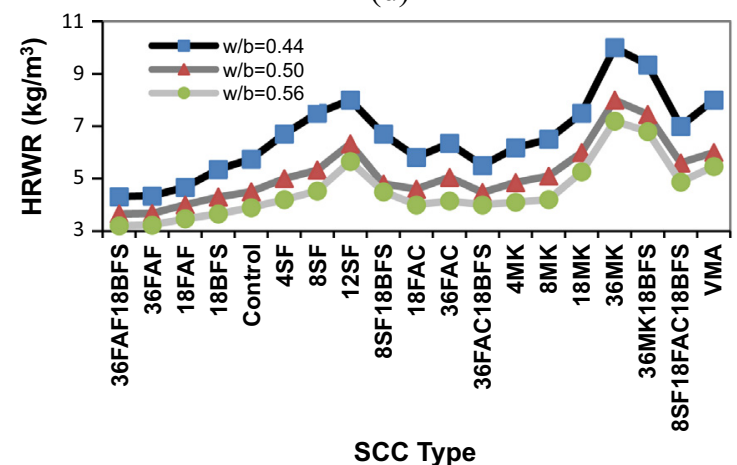

Fig. 4. HRWR demand for SCC mixtures with (a) $w / b=0.44$, (b) $w / b=0.50$, (c) $w / b=0.56$ and (d) different $w / b$ ratio.

Not only the shape and surface texture of FA particles, but also the loss on ignition (LOI), sulfate content, and particle size distribution of FA particles are factors that influence the HRWR requirements of cement pastes and concretes containing FA. Previous observation showed that $w / b$ ratio or HRWR needed to obtain a paste of normal consistency is greater for FA with high carbon content, irregular or harsh grain content or with large mean grain size [32-34]. From Fig. 4a-c, it can be noticed that all mixtures containing FAC require additional HRWR to secure the target slump flow value, as compared to the control mixtures. The increase in HRWR demand was negligible in binary mixtures containing lower amount of FAC but it was considerable when FAC content was increased. This can be attributed to the irregular and cellular surface and high porosity of the grains (Fig. 2b), as well as high fineness. On the other hand, in all $w / b$ ratios, in spite of having a higher LOI than FAC, FAF exhibited the lowest HRWR demand values in binary and ternary mixtures. The low HRWR demand in the mixtures containing FAF can be ascribed to the spherical morphology, smooth surface texture of the grains and low porosity of the particles (Fig. 2c) and lower fineness.

Finally, the effect of $w / b$ ratio on the HRWR demand is shown in Fig. 4d. As expected HRWR contents increased as the $w / b$ decreased. It is also possible to conclude that the trend of HRWR demand (the shape of curves in Fig. 4d) was similar for all $w / b$. In other words, the variation of HRWR demand with the binder system followed the same behavior regardless of the $w / b$ ratio. Fig. $4 \mathrm{~d}$ also shows that for a given binder system, the increase in HRWR demand between the mixtures with $w / b=0.50$ and 0.56 was not as significant as the increase between the mixtures with $w / b=0.50$ and 0.44 (the lower two curves in Fig. $4 \mathrm{~d}$ are closer to each other).

\subsection{Plastic viscosity}

The variations of plastic viscosity values for binary, ternary and quaternary mixtures containing SCM and VMA are demonstrated in Fig. 5a-c. For all $w / b$ ratios, the partial replacement of PC by FAC, FAF and MK have increased plastic viscosity of control mixtures (see the mixtures at the right hand side of the control mixtures in these figures). Highest increase was observed in $36 \mathrm{MK}$ mixture with $0.50 \mathrm{w} / \mathrm{b}$ ratio whose plastic viscosity was approximately $90 \%$ greater than the viscosity of the control mixture. On the other hand, for all $w / b$ values, plastic viscosity was reduced when SF and BFS were incorporated in the binder systems (Fig. 5a-c). $12 \%$ replacement of SF in the mixture with $0.44 \mathrm{w} / \mathrm{b}$ ratio resulted in the greatest reduction (approximately 2.3 times less) in plastic viscosity. The amount of reduction was less as the replacement level of SF was decreased. This behavior was contrary to the behaviors of MK and FAC: as the percentage of MK and FAC was increased, plastic viscosity also increased. Meanwhile, except for the mixture with $w / b$ ratio of 0.44 , negligible reduction in plastic viscosity was observed when amount of FAF was increased. Moreover, it can be emphasized that among the SCM having extremely high fineness, addition of SF has a more significant effect on the mixture viscosity compared to that of MK at the same level of cement replacement. These results are in agreement with other studies $[6,10,18,20,27,35]$.

Lower plastic viscosity of the mixtures containing SF can be related to difference in the volume of the binders. Owing to the difference between the specific gravity of cement and SF, mixtures containing SF had greater binder volumes causing reduction in plastic viscosity values. Note that SF has the lowest specific gravity among the SCMs used in this study. Another reason for reduction of plastic viscosity with increasing percentage of SF can be attributed to the higher packing density of SF mixtures when compared to that of PC mixtures. There is an assumption that spherical particles typically pack better than irregularly-shaped ones [33]. SF particles owing to have spherical morphology can pack better than PC particles. Increasing the packing density can reduce shear stress to enhance the flow by filling the voids and providing additional 
(a)

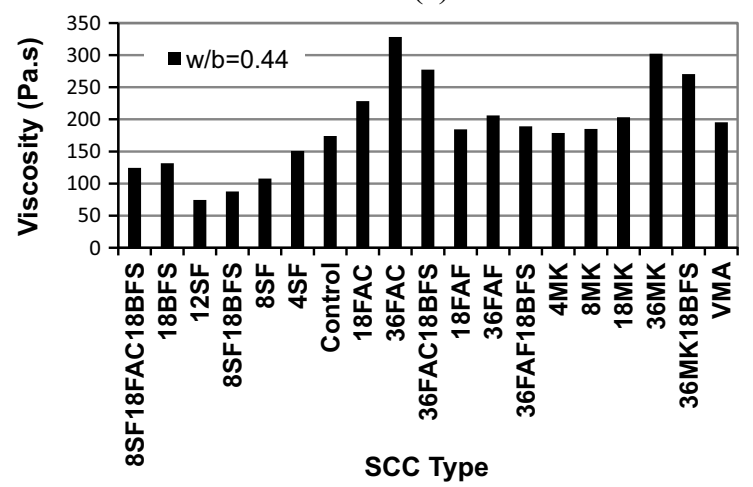

(c)

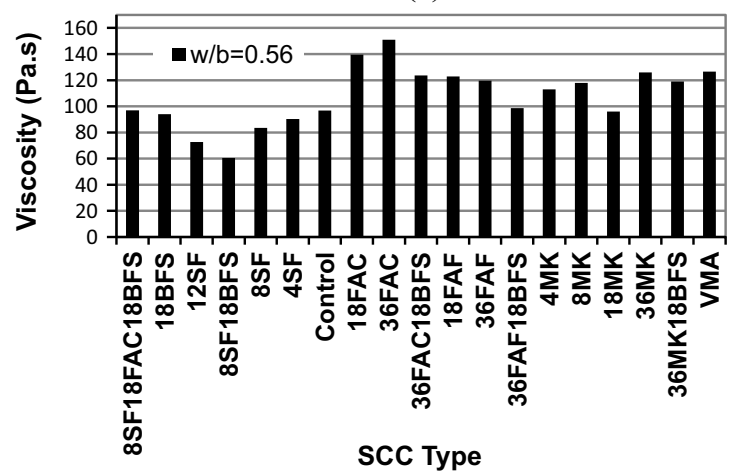

(b)

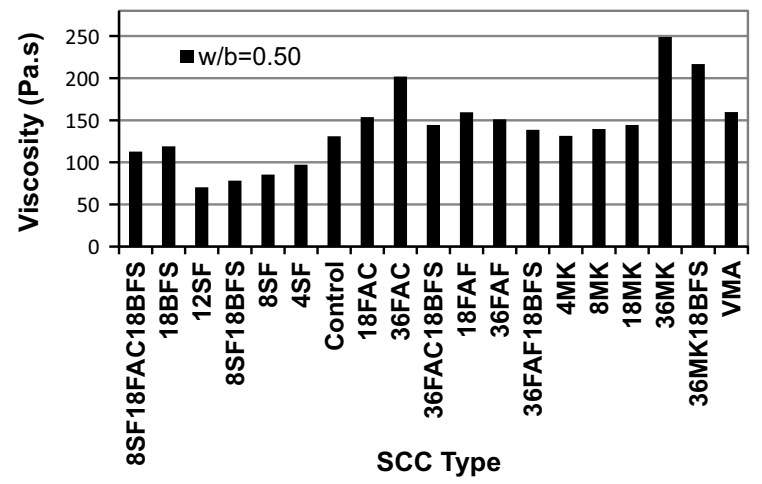

(d)

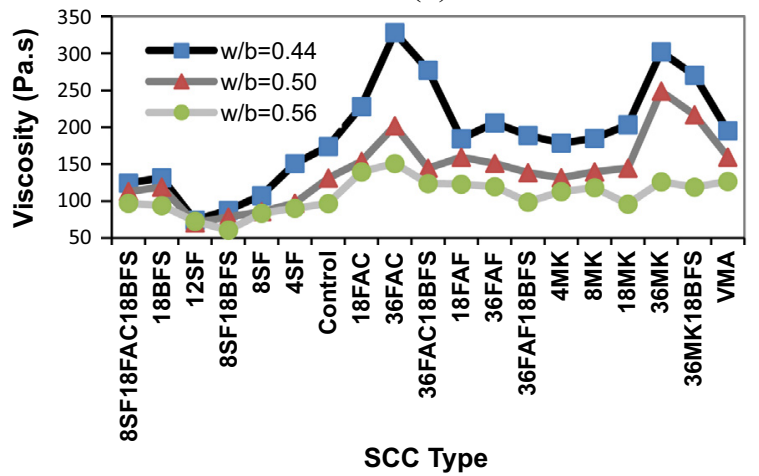

Fig. 5. Variation of plastic viscosity in SCC mixtures made with various SCM having (a) $w / b=0.44,(\mathrm{~b}) w / b=0.50$, (c) $w / b=0.56$ and (d) different $w / b$.

lubrication [36]. Spherical shape and smooth surfaces of SF particles can also lead to the lower plastic viscosity of the mixtures incorporating SF.

Morphology was again an important factor that affected the plastic viscosity of the mixtures with MK: contrary to the lubrication effect of spherical shape and smooth surface (as was the case in SF), open pores at the surface, elongated shape, irregular surface texture of the MK particles increased the plastic viscosity. The same result was reported by Cassagnabere et al. [30]. Meanwhile, MK particles, owing to their high porosity, can absorb water and HRWR, leading to a reduction in inter-particle distance between solid particles and an increase in the level of attractive forces within solid particles that can be significant sake for obtaining high plastic viscosity values.

The higher plastic viscosity values obtained for FAC mixtures in comparison with FAF one can be related to grain shape of former SCM. As shown in (Fig. 2c), FAF particles have spherical shape which typically pack better than irregularly-shaped FAC particles and can lead to a higher ball-bearing effect to reduce interparticle friction, thereby enhancing workability and reduction in plastic viscosity.

In general a moderate viscosity seems to be necessary to produce desired SCC mixtures to generate enough flow without any segregation. For a given application, plastic viscosity values should be adjusted to various requirements. A high amount of plastic viscosity can reduce concrete flowability and workability, whereas a very low-viscosity can accelerate the speed of segregation. As discussed above, use of some SCM in SCC mixtures may change amount of plastic viscosity of mixtures irrationally. For example $88 \%$ enhancing and $230 \%$ reduction of plastic viscosity in $w /$ $b=0.44$ mixtures containing 36\% FAC and $12 \%$ SF, respectively, probably is undesirable. Due to these opposite effects, combinations of SCM have found significant importance to study in this investigation. The cement containing $8 \%$ SF, 18\% FAC and 18\% BFS (quaternary system) led to a decrease in plastic viscosity relative to the mixture containing only PC and 18\% FAC in all $w / b$ ratios. Besides in all ternary systems, use of $18 \%$ BFS with other SCM resulted in a considerable decrease in plastic viscosity compared to those of binary systems without BFS. The reason why ternary systems have lower plastic viscosity can be explained as follows: Hydration of PC increases the solid volume concentration, thus increasing the viscosity. When BFS is incorporated, the amount of $\mathrm{SCM}$ in the system is increased and the magnitude of restructuring and strength of inter-particle links can be reduced due to lower reactivity of such materials than PC. Thus, the bond between two cement particles may be stronger than the bond between two slag particles or the bond between a slag and a cement particle. Therefore, lower plastic viscosity of the mixtures containing BFS compared to those without BFS was an expected observation.

As seen in Fig. 5a-c, the plastic viscosity of VMA mixtures was higher than that of control mixtures. In fresh concrete, the mixing water tends to be physically adsorbed by hydrogen and ionic bonding to the long chain polymers of the VMA. Besides, those molecules may develop attractive forces among each other, to form a gel and inter-particle links causing higher cohesiveness, thereby, greater plastic viscosity. Depending on the VMA dosage, its effect on SCC rheology can be altered. In this study, only a single dosage, which lies between the range recommended by the manufacturer, was used. It was aimed to see whether VMA can be an alternative material to SCM, when they are not available or feasible to use, for the benefit of increasing the plastic viscosity (which may be necessary for higher stability of SCC), without significantly altering the other SCC properties. The results of this study showed that VMA resulted in comparable plastic viscosity and HRWR demand with other SCM. 
As plotted in Fig. $5 d$, in rich $(w / b=0.44)$ SCC mixtures, varying the binder system had a significant effect on plastic viscosity relative to lean SCC mixtures. In other words, the effect of SCM type and amount was more observable when $w / b$ was lower. For instance, the difference between the control mixture and 36\% MK mixture was $73 \%$ for $w / b$ of 0.44 while it was only $30 \%$ when $w / b$ was 0.56 . Also it should be emphasized that the trend of change of plastic viscosity with binder system was similar irrespective of $w / b$ ratio of the mixtures (Fig. $5 \mathrm{~d}$ ).

As mentioned earlier, in all SCC mixtures amount of water was kept constant and different $w / b$ values were achieved by varying the binder content. Accordingly, the relative content of aggregate increased with the reduction in binder content as $w / b$ ratio was increased (Tables 2-4). It is well known that the amounts of binder and aggregate are two important factors affecting plastic viscosity of SCC mixtures. The increase in the concentration of aggregate can lead to higher degree of internal friction, to produce greater encounter and resistance to flow, thereby resulting in greater plastic viscosity. On the other hand, for constant water contents, mixtures with higher binder contents result in higher degree of cohesiveness, progressive tendency to formation of a gel structure and interparticle links and developing internal networks. Therefore, greater amount of plastic viscosity is expected in rich mixtures [10,37]. As shown in Fig. 5d plastic viscosity values decreased as $w / b$ was increased. From these results it can be emphasized that among these two opposite effects on plastic viscosity values, (high aggregate content and low binder content), the effect of reduction in binder content (or increase in $w / b$ ratio) was dominated over the increase of aggregate content.

\subsection{Yield stress}

Low yield stress can be regarded as the main property that makes a concrete self-consolidating. However, a very low yield stress can indicate segregation, suggesting the importance of monitoring the yield stress in SCC mixtures.

The results of yield stress for all the mixtures having a constant slump flow diameter of $(650 \mathrm{~mm})$ are presented in Table 5 and Fig. 6. As seen, the vales are quite low (max. $54 \mathrm{~Pa}$ ), indicating proper values for SCC.

As mentioned earlier, in this investigation the dosage of required HRWR to secure target slump flow value was variable. Measurement of the yield stress at a constant HRWR was not possible because of limited capacity of rheometer. Literature shows that there is a well correlation between slump flow and yield stress [38-40]. Therefore, when slump flow is kept constant, a wide range of difference in yield stress values is not expected in different mixtures. This was also the case in this study; however, the change of yield stress with binder system was still observable. SF and MK were two remarkable SCM that had most significant influence on the yield stress of the mixtures regardless of their $w / b$ ratios. As SF and MK contents increased, the yield stress also increased. The yield stress of the mixtures with SCM was higher than that of the control mixtures. Obtaining a greater yield stress with utilization of the SCM can be pertaining to higher surface area of these materials (Table 1). Enhancing surface area increases the interaction between solid particles thereby increases yield stress values.

As illustrated in Fig. 6 yield stress values increased as $w / b$ ratios were increased. This statement seems to be contrary to the well-known facts but recall that in this study slump flow was kept constant and HRWR content was adjusted for the target slump flow. Since the mixtures with higher $w / b$ ratio required lower amounts of HRWR (Fig. 4d), such mixtures had lower yield stress values, emphasizing the importance of HRWR on yield stress. Moreover, aggregate content can be another factor affecting the yield stress values. The higher aggregate concentration (as it is case for higher $w / b$ mixtures) enhances greater collision and resistance to initiation of flow, resulting in a greater yield stress. In this study, $w / b$ ratio was varied by keeping the water content constant and changing the binder content, resulting in different aggregate contents. Thus for higher $w / b$ ratio, aggregate content of the mixture was higher resulting in a higher yield stress.

Fig. 6 also shows that the trends of change of yield stress of different SCM combinations were generally similar to each other for all $w / b$ ratios except a few mixtures such as the ones with MK and FAF for $w / b=0.44$.

\subsection{V-funnel time}

The V-funnel time test can be applied to evaluate indirectly the flowability and viscosity of SCC. In fact this time value characterizes the rate of flow and is affected by the potential deformability of concrete. Although it cannot measure the amount of viscosity of SCC, but a relationship between flow time and viscosity

Table 5

Rheological properties of the SCC mixtures having slump flow at $650 \mathrm{~mm}$.

\begin{tabular}{|c|c|c|c|c|c|c|c|c|c|c|c|c|}
\hline Mixture ID & $w / b$ & $\begin{array}{l}\text { Pl. visc. } \\
\text { (Pa s) }\end{array}$ & $\begin{array}{l}\text { Yield stress } \\
(\mathrm{Pa})\end{array}$ & $\begin{array}{l}\text { V-f time } \\
\text { (s) }\end{array}$ & $w / b$ & $\begin{array}{l}\text { Pl. visc. } \\
\text { (Pa s) }\end{array}$ & $\begin{array}{l}\text { Yield stress } \\
(\mathrm{Pa})\end{array}$ & $\begin{array}{l}\text { V-f time } \\
\text { (s) }\end{array}$ & $w / b$ & $\begin{array}{l}\text { Pl. visc. } \\
\text { (Pa s) }\end{array}$ & $\begin{array}{l}\text { Yield stress } \\
(\mathrm{Pa})\end{array}$ & $\begin{array}{l}\text { V-f time } \\
\text { (s) }\end{array}$ \\
\hline Control & 0.44 & 174 & 10.0 & 16 & 0.50 & 131 & 23.2 & 19 & 0.56 & 96.7 & 31.2 & 21 \\
\hline $4 \mathrm{SF}$ & 0.44 & 150.8 & 26.2 & 15 & 0.50 & 97.2 & 35.8 & 17 & 0.56 & 90.3 & 43.7 & 19 \\
\hline $8 S F$ & 0.44 & 107.7 & 26.5 & 13 & 0.50 & 85.6 & 41.0 & 15 & 0.56 & 83.5 & 43.1 & 17 \\
\hline $12 \mathrm{SF}$ & 0.44 & 74.3 & 35.0 & 8 & 0.50 & 70.4 & 46.3 & 10 & 0.56 & 72.7 & 54.3 & 13 \\
\hline 8SF18BFS & 0.44 & 87.6 & 32.2 & 12 & 0.50 & 78.2 & 42.5 & 15 & 0.56 & 60.5 & 44.2 & 14 \\
\hline $18 \mathrm{FAC}$ & 0.44 & 228.3 & 11.1 & 21 & 0.50 & 153.7 & 27.2 & 24 & 0.56 & 139.6 & 31.9 & 27 \\
\hline $36 \mathrm{FAC}$ & 0.44 & 328.3 & 14.5 & 25 & 0.50 & 202 & 27.0 & 28 & 0.56 & 151 & 30.6 & 34 \\
\hline 36FAC18BFS & 0.44 & 277.5 & 17.6 & 22 & 0.50 & 144.5 & 33.9 & 22 & 0.56 & 98.7 & 36.9 & 24 \\
\hline 18FAF & 0.44 & 184.5 & 16.2 & 14 & 0.50 & 159.5 & 29.6 & 17 & 0.56 & 122.9 & 44.3 & 18 \\
\hline 36FAF & 0.44 & 206.1 & 21.4 & 14 & 0.50 & 151.1 & 25.1 & 17 & 0.56 & 119.6 & 41.7 & 19 \\
\hline 36FAF18BFS & 0.44 & 189 & 27.0 & 12 & 0.50 & 138.6 & 31.5 & 15 & 0.56 & 98.7 & 44 & 18 \\
\hline $4 \mathrm{MK}$ & 0.44 & 178.6 & 22.3 & 18 & 0.50 & 131.6 & 26.1 & 18 & 0.56 & 113 & 32.1 & 20 \\
\hline $8 \mathrm{MK}$ & 0.44 & 184.9 & 20.7 & 20 & 0.50 & 139.6 & 29.6 & 20 & 0.56 & 118 & 35.2 & 22 \\
\hline $18 \mathrm{MK}$ & 0.44 & 203.3 & 23.4 & 19 & 0.50 & 144.5 & 35.4 & 21 & 0.56 & 95.9 & 38.7 & 21 \\
\hline 36MK & 0.44 & 302.2 & 14.6 & 24 & 0.50 & 248.8 & 31.3 & 29 & 0.56 & 126 & 34.7 & 30 \\
\hline 36MK18BFS & 0.44 & 270.5 & 15.3 & 21 & 0.50 & 216.8 & 36.9 & 26 & 0.56 & 119 & 41.2 & 27 \\
\hline 18BFS & 0.44 & 131.6 & 9.30 & 15 & 0.50 & 119 & 29.8 & 18 & 0.56 & 94 & 36.2 & 20 \\
\hline 8SF18FAC18BFS & 0.44 & 124.3 & 28.8 & 14 & 0.50 & 112.8 & 35.3 & 17 & 0.56 & 96.9 & 40.7 & 18 \\
\hline VMA & 0.44 & 195.4 & 25.8 & 18 & 0.50 & 159.8 & 30.7 & 22 & 0.56 & 126.6 & 33.9 & 23 \\
\hline
\end{tabular}

Notes: Pl. visc: Plastic viscosity; V-f: V-funnel. 


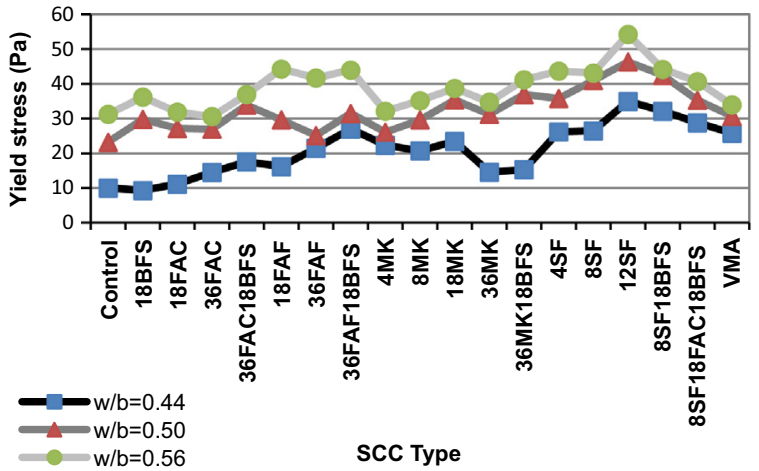

Fig. 6. Variation of yield stress in SCC mixtures made with various SCM.

can be estimated [39]. Several researchers found good correlations between these parameters $[10,18]$.

The V-funnel times obtained from 57 SCC mixtures with three $w / b$ ratios are presented in Table 5 . These values were ranged from 8 to $25 \mathrm{~s}$ for mixtures with $w / b$ ratio of $0.44,10-29 \mathrm{~s}$ for mixtures with $w / b$ ratio of 0.50 , and $13-34 \mathrm{~s}$ for those having $0.56 w / b$ ratio. Such significant difference in flow time for the mixtures having same $w / b$ ratio was due to the use of SCM with very diverse properties in these mixtures.

SF had significant influence on V-funnel time. As the amount of $\mathrm{SF}$ was increased, reduction in flow time values was visible. Also reduction in flow time values was observed with the use of FAF and BFS in SCC mixtures. On the other hand, adding MK, FAC, and VMA increased flow time values in all of the mixtures, irrespective of their $w / b$ ratio. The binder containing 36\% MK or $36 \%$ FAC increased V-funnel times up to 30 and $34 \mathrm{~s}$ respectively, in the mixture having $w / b$ ratio of 0.56 , while that of control mixture with same $w / b$ ratio was only $21 \mathrm{~s}$.

The relationship between flow time and plastic viscosity for the mixtures having different $w / b$ ratios are plotted in Fig. 7a-c. Good relationships between $\mathrm{V}$-funnel time and plastic viscosity, with $R^{2}$ values ranging between 0.73 and 0.81 , were observed.

HRWR content, binder content and aggregate content are among the factors affecting the flow time of SCC. Greater concentration of HRWR in the solution can enhance fluidity of the mixtures and reduce flow time values. The increase in the concentration of aggregate increases the degree of internal friction and reduces the mobility of the concrete [37]. Also increasing aggregate content can lead to greater risk of collision among coarse aggregate particles at the tapered outlet of the V-funnel [10]. In this study, increase in the flow time values in mixtures with low binder content and high concentration of aggregate was observed (Fig. 7d).

European Guidelines [41] provides a classification of SCC viscosity according to V-funnel times. The mixtures having a V-funnel time between 9 and $25 \mathrm{~s}$ are classified as VF2. Among the $57 \mathrm{mix}$ tures prepared in this study, 50 of them belong to this category, while the remaining five mixtures showed flow times greater than $25 \mathrm{~s}$. It can also be noted that according to the same guidelines, the slump flow of the mixtures $(650 \mathrm{~mm})$ used in this study can be classified as SF1, which corresponds to slump flow values ranging between 550 and $650 \mathrm{~mm}$.

\section{Conclusion}

The rheological properties of an SCC mixture containing a certain type and amount of SCC can be affected by the test methods (such as rheometer type) and material characteristics. Therefore, it (a)

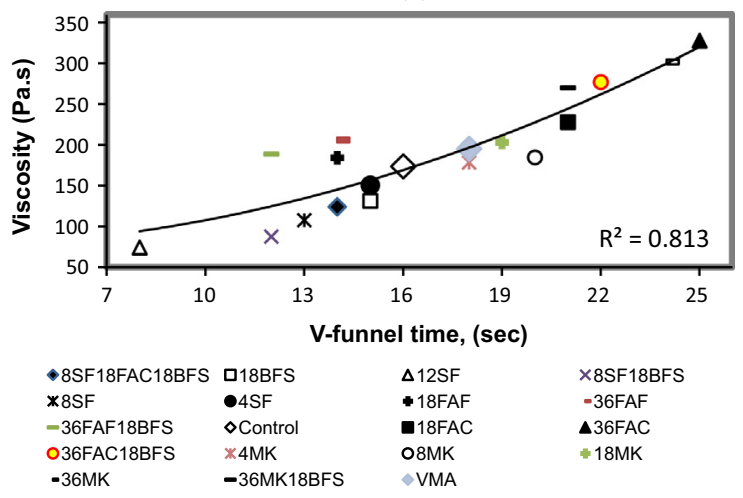

(c)

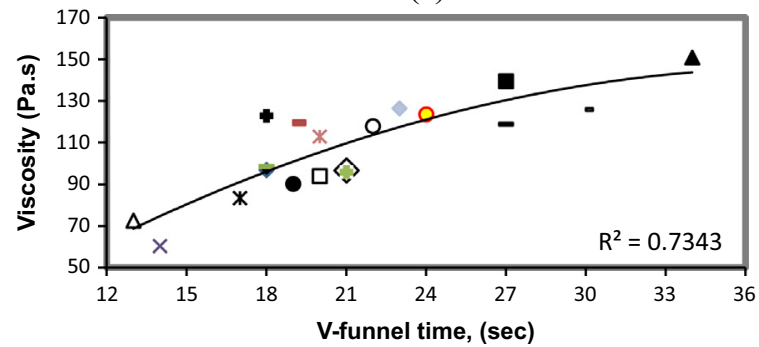

(b)

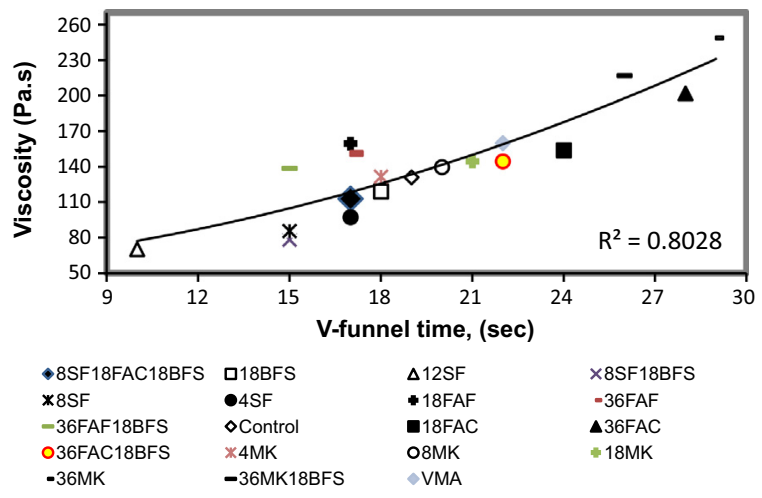

(d)

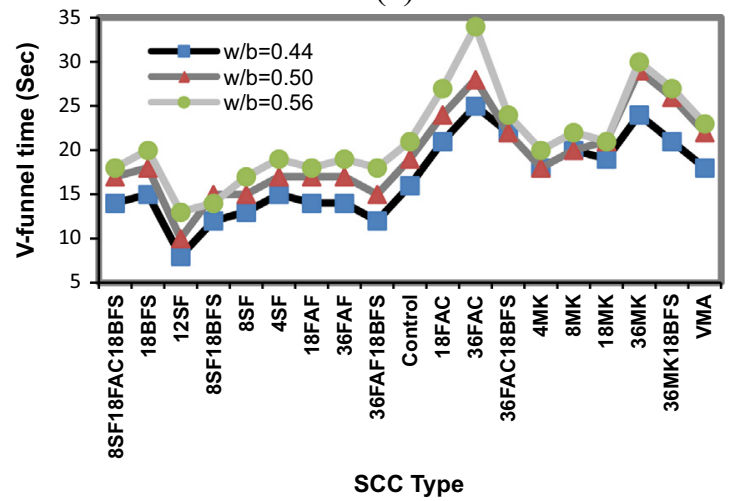

Fig. 7. Relationship between the V-funnel time and plastic viscosity for mixtures having (a) $w / b=0.44$, (b) $w / b=0.50$, (c) $w / b=0.56$ and (d) different $w / b$ ratio. 
should be kept in mind that the following conclusions were derived for the materials used and tests applied in this study:

1. For the same slump flow values, mixtures containing SF, MK and FAC showed higher the HRWR demand compared to that of mixtures made with FAF, BFS and only PC. Incorporation of greater contents of SF, MK and FAC necessitated greater HRWR than control mixtures.

2. In all $w / b$ ratios, SF submitted highest and FAF exhibited the lowest HRWR demand in SCC mixtures. Incorporation of BFS to obtain ternary and quaternary mixtures decreased HRWR demand, compared to that of counterpart mixtures without BFS.

3. In all SCC mixtures HRWR contents increased as the $w / b$ ratio decreased. The variation of HRWR demand with the binder system followed the same behavior for all $w / b$ ratios. The difference between HRWR demand of the mixtures having $w / b$ ratios of 0.5 and 0.56 was not as significant as the difference between HRWR demand of mixtures having $w / b$ ratio of 0.50 and 0.44 .

4. Plastic viscosity of the mixtures containing FAC, FAF, MK or VMA was higher than that of the control mixtures, regardless of the $w / b$ ratio. The highest increase (90\%) in plastic viscosity was observed in $36 \%$ MK mixture with $w / b$ ratio of 0.50 . As the percentage of MK and FAC was increased, plastic viscosity was also increased.

5. Plastic viscosity was reduced when SF and BFS were incorporated with $\mathrm{PC} .12 \%$ replacement of SF in the mixture having $w / b$ ratio of 0.44 reduced the plastic viscosity value approximately 2.3 times.

6. The quaternary system containing $8 \% \mathrm{SF}, 18 \%$ FAC and $18 \%$ BFS led to a decrease in plastic viscosity relative to the mixture containing only PC. Also in all ternary systems, use of $18 \%$ BFS with other SCM resulted in a considerable decrease in plastic viscosity compared to those of binary systems without BFS.

7. Among the SCM having extremely high fineness, addition of SF has a more significant effect on the mixture viscosity compared to incorporation of MK at the same level of cement replacement. The change of plastic viscosity with the binder system was more significant as the $w / b$ was decreased.

8. Plastic viscosity decreased as $w / b$ ratio was increased. Since the water content of the mixtures was kept constant, any increase in $w / b$ ratio caused reduction in binder content and consequent increase in aggregate content. Among two factors having opposite effects on plastic viscosity the former was dominated over the latter. The trend of change of plastic viscosity with binder system was similar for different $w / b$ ratios.

9. The yield stress of the mixtures with SCM was higher than that of the control mixtures. Having considerably higher finenesses than the others, SF and MK were two remarkable SCM that had most significant influence on the yield stress values for all $w / b$ ratios.

10. Yield stress values were higher for the mixtures with higher $w / b$ ratios. Although this conclusion seems unexpected, it could be due to the lower HRWR requirements and higher aggregate contents of these mixtures.

11. Use of SF, FAF and BFS in SCC mixtures reduced the V-funnel flow times while addition of MK, FAC and VMA increased the flow times.

12. V-funnel test was found to be successful in indicating the plastic viscosity for a given $w / b$ ratio since good correlations were established between plastic viscosity and V-funnel flow time values for each $w / b$. However, the test failed to correlate these parameters when $w / b$ was changed.

13. SCC has to be designed to have adjusted rheological properties considering a given application since the required yield stress or plastic viscosity of the mixtures would not be the same in all cases. SCM were found useful for this adjustment.

\section{Acknowledgment}

This paper is a part of a more extensive study supported by TUBITAK (The Scientific and Technological Research Council of Turkey) under the grant of $112 \mathrm{M} 581$. The authors would like to acknowledge this support.

\section{References}

[1] Petit JY, Wirquin E, Vanhove Y, Khayat K. Yield stress and viscosity equations for mortars and self-consolidating concrete. Cem Concr Res 2007;37:655-70.

[2] Erdem TK, Khayat K, Yahia A. Correlating rheology of self-consolidating concrete to corresponding concrete-equivalent mortar. ACI Mater J 2009;106(2):154-60.

[3] Khayat K. Optimization and performance of air-entrained, self compacting concrete. ACI Mater J 2000;97(5):526-35.

[4] Sahmaran M, Lachemi M, Erdem TK, Yucel HE. Use of spent foundry sand and fly ash for the development of green self-consolidating concrete. Mater Struct 2011;44:1193-204.

[5] Sahmaran M, Christianto HA, Yaman IO. The effect of chemical admixtures and mineral additives on the properties of self-compacting mortars. Cem Concr Compos 2006;28:432-40.

[6] Khayat K, Yahia A, Sayed M. Effect of supplementary cementitious materials on rheological properties, bleeding, and strength of structural grout. ACI Mater J 2008;105(6):585-93.

[7] Bouzoubaa N, Lachemi M. Self compacting concrete incorporating high volumes of Class F fly ash preliminary results. Cem Concr Res 2011;31:413-20.

[8] Habert G, Roussel N. Study of two concrete mix-design strategies to reach carbon mitigation objectives. Cem Concr Compos 2009;31:397-402.

[9] Vejmelkova E, Keppert M, Grzeszczyk S, Skalinski B, Cerny R. Properties of selfcompacting concrete mixtures containing metakaolin and blast furnace slag. Constr Build Mater 2011;25:1325-31.

[10] Assaad J. Formwork pressure of self-consolidating concrete influence of thixotropy. PhD Thesis, University of Sherbrooke, Sherbrooke; 2004.

[11] Uysal M, Akyuncu V. Durability performance of concrete incorporating Class $f$ and Class c fly ashes. Constr Build Mater 2012;34:170-8.

[12] Mehdipour I, Seyed Razzaghi M, Amini K, Shekarchi M. Effect of mineral admixtures on fluidity and stability of self-consolidating mortar subjected to prolonged mixing time. Constr Build Mater 2013;40:1029-37.

[13] Uysal M, Sumer M. Performance of self-compacting concrete containing different mineral admixtures. Constr Build Mater 2011;25:4112-20.

[14] Guneyisi E, Gesoglu M, Ozbay E. Permeation properties of self-consolidating concretes with mineral admixtures. ACI Mater J 2011;108(2):150-8.

[15] Sahmaran M, Ozkan N, Keskin SB, Uzal B, Yaman IO, Erdem TK. Evaluation of natural zeolite as a viscosity-modifying agent for cement-based grouts. Cem Concr Res 2008;38:930-7.

[16] Hassan AA, Lachemi M, Hossain K. Effect of metakaolin and silica fume on the durability of self-consolidating concrete. Cem Concr Compos 2012;34:801-7.

[17] Gesoglu M, Guneyisi E, Ozbay E. Properties of self-compacting concretes made with binary, ternary and quaternary cementitious blends of fly ash, blast furnace slag and silica fume. Constr Build Mater 2009;23:1847-54.

[18] Hassan A, Lachemi M, Hossain K. Effect of metakaolin and silica fume on rheology of self-consolidating concrete. ACI Mater J 2012;109(6):657-64.

[19] Mouret M, Cyr M. Rheological characterization of super-plasticized cement pastes containing mineral admixtures: consequences on self-compacting concrete. In: Malhotra VM, editor. Proceedings of 7th CANMET/ACI Inter. Conference, SP-217, MI; 2003. p. 241-55.

[20] Boukendakdji O, Kadri E-H, Kenai S. Effects of granulated blast furnace slag and superplasticizer type on the fresh properties and compressive strength of selfcompacting concrete. Cem Concr Compos 2012;34:583-90.

[21] Yahia A, Tanimura M, Shimabukuro A, Shimoyama Y. Effect of rheological parameters on self compactability of concrete containing various mineral admixtures. In: Proceedings of the first RILEM international symposium on self-compacting concrete, Stockholm; 1999. p. 523-35.

[22] Sahmaran M, Yaman O, Tokyay M. Development of high-volume low-lime and high-lime fly-ash-incorporated self-consolidating concrete. Mag Concr Res 2007;59:97-106

[23] ASTM C150-12. Standard specification for Portland cement. ASTM International; 2012.

[24] ASTM C494-08. Standard specification for chemical admixtures for concrete. ASTM International; 2012.

[25] Khayat KH, Bickley J, Lessard M. Performance of air-entrained, self consolidating concrete for casting basement and foundation walls. ACI Mater J 2000;97(5):374-80.

[26] Skarendahl A, Peterson SO. Self-compacting concrete. State of the art report of RILEM TC174-SCC, France; 2000. p. 47-55.

[27] Ferraris CF, Obla KH, Hill R. The influence of mineral admixtures on the rheology of cement paste and concrete. Cem Concr Res 2001;31:245-55. 
[28] Caldarone MA, Gruber KA, Brug RG. High-reactivity metakaolin: a new generation mineral admixture. Concr Int 1994;16:34-40.

[29] Paiva H, Velosa A, Cachim P, Ferreira VM. Effect of metakaolin dispersion on the fresh and hardened state properties of concrete. Cem Concr Res 2012;42:607-12.

[30] Cassagnabere F, Diederich P, Mouret M, Escadeillas G, Lachemi M. Impact of metakaolin characteristics on the rheological properties of mortar in the fresh state. Cem Concr Compos 2013;37:95-107.

[31] Wild S, Khatib JM, Jones A. Relative strength pozzolanic activity and cement hydration in super plasticized metakaolin concrete. Cem Concr Res 1996;26:1537-44.

[32] Paya J, Monzo J, Borrachero MV, Perris E, Amahjour F. Thermogravimetric methods for determining carbon content in fly ashes. Cem Concr Res 1998;28:675-86.

[33] Bentz DP, Ferraris CF, Galler MA, Hansen AS, Guynn JM. Influence of particle size distributions on yield stress and viscosity of cement-fly ash pastes. Cem Concr Res 2012;42:404-9.

[34] Gengying L, Xiaozhong W. Influence of fly ash and its mean particle size on certain engineering properties of cement composite mortars. Cem Concr Res $2005 ; 35: 1128-34$
[35] Shi YX, Matsui I, Guo YJ. A study on the effect of fine mineral powders with distinct vitreous contents on the fluidity and rheological properties of concrete. Cem Concr Res 2004;34:1381-7.

[36] Tattersall GH, Banfill PFG. The rheology of fresh concrete. London: Pitman advanced publishing program; 1983.

[37] Assaad J, Khayat KH. Formwork pressure of self consolidating concrete made with various binder types and contents. ACI Mater J 2005;102(4): 215-23.

[38] European Union Growth Contract No. G6RD-CT-2001-00580. Final Report: Measurement of properties of fresh self-compacting concrete; 2005.

[39] Wallevik JE. Relationship between the Bingham parameters and slump. Cem Concr Res 2006:36:1214-21.

[40] Roussel N. Correlation between yield stress and slump: comparison between numerical simulations and concrete rheometer results. Mater Struct 2006;39(4):501-9.

[41] EFNARC. Self compacting concrete, European project group. The European guidelines for self-compacting concrete: specification, production and use; 2005. 